\title{
Pyrolysis of municipal sludge without gas protection and its adsorption performance toward tetracycline: Effect of pyrolysis temperature and $\mathrm{KOH}$ activation
}

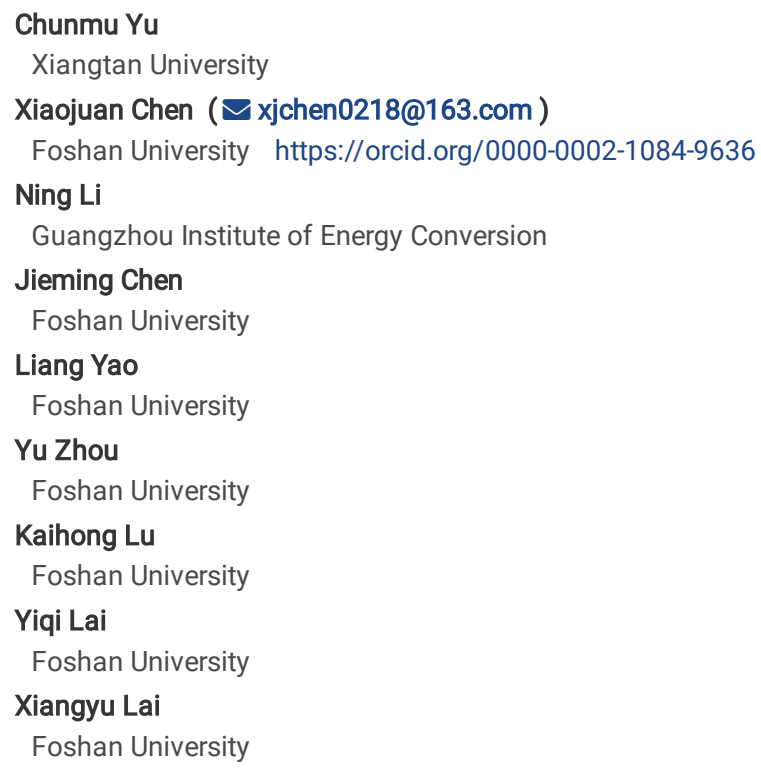




\begin{abstract}
Large amount of municipal sludge is difficulty to handle, its resource utilization is an effective measure. In this study, the municipal sludge from sewage treatment plant was pyrolyzed without nitrogen protection at different temperatures and $\mathrm{KOH}$ concentrations for activation. The pyrolysis products with higher surface aera and enriched pore structures could be obtained at the pyrolysis temperature of $500{ }^{\circ} \mathrm{C}$, and $\mathrm{KOH}$ activation could further increase the surface aera of the products. The maximum specific surface area was $44.71 \mathrm{~m}^{2} / \mathrm{g}$, which was obtained under $2 \mathrm{~mol} / \mathrm{L} \mathrm{KOH}$ activation before pyrolysis at $500{ }^{\circ} \mathrm{C}$. And in this situation, the obtained pyrolysis products showed the maximum adsorption capacity of $50.75 \mathrm{mg} / \mathrm{g}$ toward tetracycline (TC). Moreover, the TC adsorption onto various pyrolysis products followed the pseudo-second-order kinetic model. Adsorption thermodynamics analysis suggested the TC adsorption onto products obtained at pyrolysis temperature of $500{ }^{\circ} \mathrm{C}$ was mainly the multi-molecule heterogeneous adsorption, while the TC adsorption onto pyrolysis product pretreated through the activation of $\mathrm{KOH}$ followed the monomer adsorption mechanism. This different adsorption mechanism was largely related to the pore structure, polarity, and aromaticity etc. of the adsorbent.
\end{abstract}

\title{
1. Introduction
}

The load of urban sewage treatment system has been aggravated by the rapid urbanization process, leading to the massive production of municipal sludge (Wang et al. 2017). According to statistics, the quantity of municipal sludge with water content of $80 \%$ in China has reached 60 million tons in 2019 (Dai 2020). Due to the special source of municipal sludge, it contains some harmful ingredients of parasite eggs, pathogenic microorganisms and heavy metals. Therefore, many technologies have been developed to dispose the municipal sludge, mainly including security landfill and incineration. But these technologies should also cause serious waste of resources and secondary pollution (Chun et al. 2012). Considering that the municipal sludge is a kind of biomass with many organic and inorganic components, maybe its resource utilization is a good strategy.

In recent years, main strategies including supercritical water oxidation, incineration power generation and preparation of multifunctional materials (such as biochar materials) have been employed to realize the resource utilization of municipal sludge (Shi et al. 2014; Yan et al. 2020). The use of municipal sludge to prepare multifunctional materials is currently a hot topic because of its various technical methods, strong operability, and wide application (Agrafioti et al. 2013; Lu et al. 2012). A large number of studies have been done to obtain multifunctional materials through the pyrolysis method from virous biomass. The main reason is that the pyrolysis method can obtain materials with rich functional groups and high yield (Barry et al. 2019; Hossain et al. 2011).

Nevertheless, the products obtained by direct pyrolysis of biomass exhibit poor performance owing to lack of developed pore structure. Therefore, the activation pretreatment of biomass is indispensable for improving the physical and chemical properties of pyrolysis products (Chen et al. 2017). Xi and Guo (2013) prepared biochar using municipal sludge through the pyrolysis process with the activation of sulfuric acid, the adsorption capacity of obtained biochar toward $\mathrm{Cr}(\mathrm{VI})$ reached $61.3 \mathrm{mg} / \mathrm{g}$. Zhang et al. (2019) found that potassium hydroxide (KOH) activation can greatly increase the specific surface area of sludge-based biochar. The study from Jin et al. (2016) also indicated that $\mathrm{KOH}$ activation can increase the surface area and enrich the porous texture of algaedairy-manure slurry (DAS) based biochar, leading to the adsorption capacity of $\mathrm{Cu}(\mathrm{II})$ onto biochar increase from $21.12 \mathrm{mg} / \mathrm{g}$ to $50.71 \mathrm{mg} / \mathrm{g}$. Therefore, the activation pretreatment of acid or alkali is of great significance for regulating the pore structure of biochar, but the effect of pyrolysis temperature on the activation effect of acid or alkali needs to be further studied (Hossain et al. 2011). In addition, it is worth noting that the current pyrolysis process of biomass is mostly under the protection of nitrogen. Few studies have focused on the conversion and properties of biomass under pyrolysis conditions without nitrogen protection.

In this study, the municipal sludge from a municipal sewage treatment plant was employed as raw biomass, and the pyrolysis process was conducted in the muffle furnace without nitrogen protection. The different concentrations of $\mathrm{KOH}$ and pyrolysis temperatures was systematically studied to explore their effects on the physicochemical properties of pyrolysis products. Then, the pyrolysis products were used to adsorb the organic pollutant tetracycline (TC), and the characteristics of adsorption kinetics and adsorption isotherms were also discussed.

\section{Experiment And Method}

\subsection{Materials}

All chemicals used in the experiments were of analytical grade, and they were purchased from Tianxin Fine Chemical Development Corporation Ltd, Tianjing, China. Deionized water $(18.25 \mathrm{M} \Omega$ ) was used to prepare the chemical solutions. The municipal sludge was obtained from a municipal sewage treatment plant of FoShan, China. After drying at $80^{\circ} \mathrm{C}$ to make sure that the moisture was almost completely evaporated, the pretreated municipal sludge was ground and sieved to separate the particles under $0.18 \mathrm{~mm}$.

\subsection{Pyrolysis modification of municipal sludge}

The pyrolysis experiments of pretreated municipal sludge were conducted in a muffle furnace without any inert gas protection at different temperatures of $300^{\circ} \mathrm{C}, 400^{\circ} \mathrm{C}, 500^{\circ} \mathrm{C}, 600^{\circ} \mathrm{C}$ and $700^{\circ} \mathrm{C}$, respectively. The pyrolysis modified products were hereinafter referred to as S300, S400, S500, S600 and S700, respectively. The pyrolysis yield of municipal sludge was measured as the ratio of the weight of the pyrolysis products to the weight of the raw pretreated municipal sludge. Ash content in pyrolysis modified products was determined via heating the products at $650^{\circ} \mathrm{C}$ for $1.5 \mathrm{~h}$, and the mass ratio of the residue substance to the original substance was the percentage of ash. The $\mathrm{pH}$ of the pyrolysis modified products and pretreated municipal sludge were determined by dispersing a certain amount of the samples into distilled water and measuring with a pH meter (PHSJ-3F, Rex Electric Chemical).

$\mathrm{KOH}$ activation experiments were also carried out to investigate the effect of alkaline substances on the physicochemical properties of the pyrolysis modified products from the municipal sludge. Before the pretreated municipal sludge was transferred into the muffle furnace, the samples were firstly impregnated by 
$250 \mathrm{~mL}$ of $\mathrm{KOH}$ solution with different concentrations $(0.5 \mathrm{~mol} / \mathrm{L}, 1 \mathrm{~mol} / \mathrm{L}, 2 \mathrm{~mol} / \mathrm{L}$, and $4 \mathrm{~mol} / \mathrm{L})$ under vigorous stirring for 24 hours, and after that the centrifugal matter was transferred into the muffle furnace at the temperature of $500^{\circ} \mathrm{C}$ for 6 hours of pyrolysis reaction. Then, these modified products were referred to as KS0.5, KS1, KS2 and KS4 in the following content, respectively.

\subsection{Characterization of the samples}

Element content of $\mathrm{C}, \mathrm{H}, \mathrm{O}, \mathrm{N}$ in pyrolysis modified products of municipal sludge were analyzed with an elemental analyzer (Vario EL- $\varangle$, Elementar, Germany). The Brunauer-Emmett-Teller (BET) (BET, Micromeritics ASAP2020, USA) technique was used to determine the surface aeras, and Barrett-Joyner-Halenda (BJH) method was employed to investigate the pore structures. The crystal phase structure of the samples was characterized by X-ray diffraction (XRD, Bruker D8 Advance, Germany) over the $2 \theta$ range of $10-80^{\circ}$. The functional groups and surface elemental valence of the samples were detected through Fourier Transform Infrared Spectroscopy (FT-IR, Nicolet 460, USA) and X-ray photoelectron spectroscopy (XPS, Thermo Fisher Scientific, ESCALAB $250 X i)$, respectively.

\subsection{Adsorption kinetics experiments}

Adsorption kinetic experiments were performed by placing $0.2 \mathrm{~g}$ of pyrolysis modified products in a glass beaker with $250 \mathrm{~mL}$ TC solution ( $25 \mathrm{mg} / \mathrm{L})$ and agitating on a shaker at $200 \mathrm{rpm}$ at $30^{\circ} \mathrm{C}$. The supernatant was taken out using syringe at certain intervals and then filtrated through a $0.45 \mu \mathrm{m}$ PTFE filter membrane. The absorbance of filtered solution was measured with a spectrophotometer (UV2102PC, UNICO, U.S.A) at the maximum absorption wavelength of TC $(357 \mathrm{~nm})$. The standard curve method was employed to measure the concentration of TC in the solution.

The adsorption kinetic of TC onto pyrolysis modified products were evaluated by using the pseudo-first-order kinetics (Eq. (1)), pseudo-second-order kinetics (Eq. (2)) and intra-particle diffusion models (Eq. (3)).

$$
\begin{aligned}
& Q_{\mathrm{t}}=\mathrm{Q}_{\mathrm{e}}\left(1-\mathrm{e}^{-\mathrm{k}_{\mathrm{t}} \mathrm{t}}\right) \\
& \mathrm{Q}_{\mathrm{t}}=\frac{\mathrm{k}_{2} \mathrm{Q}_{\mathrm{e}}{ }^{2} \mathrm{t}}{\left(1+\mathrm{k}_{2} \mathrm{Q}_{\mathrm{e}} \mathrm{t}\right)} \\
& \mathrm{Q}_{\mathrm{t}}=\mathrm{k}_{\mathrm{i}} \mathrm{t}^{1 / 2}+\mathrm{X}
\end{aligned}
$$

Where $Q_{t}$ and $Q_{e}(\mathrm{mg} / \mathrm{g})$ are the adsorption amount of TC at time $t$ and at equilibrium time, respectively. $\mathrm{k}_{1}\left(\mathrm{~min}^{-1}\right), \mathrm{k}_{2}(\mathrm{~g} / \mathrm{mg} \cdot \mathrm{min})$, and $\mathrm{k}_{\mathrm{i}}\left(\mathrm{mg} / \mathrm{g}\right.$ min $\left.{ }^{0.5}\right)$ are the rate constants for the pseudo-first-order kinetics, pseudo-second-order kinetics and intra-particle diffusion equations, respectively. $\mathrm{X}$ (mg/g) is the model parameter of intra-particle diffusion.

\subsection{Adsorption isotherm experiment}

Adsorption isotherm experiment was performed at $30^{\circ} \mathrm{C}$ as the initial TC concentration ranges from 5 to $50 \mathrm{mg} / \mathrm{L}$. To initiate the experiments, $0.2 \mathrm{~g}$ of pyrolysis modified products was placed into a glass beaker with $250 \mathrm{~mL}$ of TC solution and then was shaken at $200 \mathrm{rpm}$ at $30^{\circ} \mathrm{C}$. The initial concentrations of TC were of 5, 10, 25, 30, $50 \mathrm{mg} / \mathrm{L}$. The adsorption amount of TC on pyrolysis modified products when the reaction reached equilibrium was calculated via Equation (4). Besides, the adsorption isotherm models of Freundlich model (Eq. (5)) and Langmuir model (Eq. (6)) were used to explore the adsorption mechanism. These Equations can be expressed as follows in detail:

$$
\begin{aligned}
& \mathrm{Q}_{\mathrm{e}}=\frac{\left(\mathrm{C}_{\mathrm{o}}-\mathrm{C}_{\mathrm{e}}\right) \mathrm{V}}{\mathrm{m}} \\
& \mathrm{Q}_{\mathrm{e}}=\mathrm{K}_{\mathrm{F}} \mathrm{C}_{\mathrm{e}}^{\mathrm{n}} \\
& \mathrm{Q}_{\mathrm{e}}=\frac{\mathrm{Q}_{\mathrm{m}} \mathrm{K}_{\mathrm{L}} \mathrm{C}_{\mathrm{e}}}{1+\mathrm{K}_{\mathrm{L}} \mathrm{C}_{\mathrm{e}}}
\end{aligned}
$$

Where $\mathrm{Q}_{\mathrm{e}}(\mathrm{mg} / \mathrm{g})$ is the adsorption amount of $\mathrm{TC}$ at equilibrium time, and $\mathrm{Q}_{\mathrm{m}}(\mathrm{mg} / \mathrm{g})$ is the maximum adsorption capacity. $\mathrm{C}_{0}$ and $\mathrm{C}_{\mathrm{e}}$ are the initial concentration and equilibrium concentration of $\mathrm{TC}(\mathrm{mg} / \mathrm{L})$, respectively. $\mathrm{m}$ is the mass of pyrolysis modified products, and $\mathrm{V}$ is the volume of $\mathrm{TC}$ solution $(\mathrm{L})$. $\mathrm{K}_{\mathrm{F}}(\mathrm{mg} / \mathrm{g})$ and $\mathrm{K}_{\mathrm{L}}(\mathrm{L} / \mathrm{mg})$ are adsorption constants in Freundlich and Langmuir model, respectively. $\mathrm{n}$ is the Freundlich linear exponent.

\section{Results And Discussion}

\subsection{General properties of the pyrolysis products}

Pyrolysis temperature has the largest effect on the quality and quantity characteristics of the products (Agrafioti et al. 2013). As shown in Fig. 1a, an increase in pyrolysis temperature resulted in a decrease in products yield. And the yield of pyrolysis products decreased significantly with increasing the pyrolysis temperature from 300 to $500^{\circ} \mathrm{C}$, while the yield barely changed with the further increase of temperature to $700^{\circ} \mathrm{C}$. The decrease in pyrolysis products yield may be related to the further pyrolysis of the initial raw materials or the secondary reactions of solid residues, and almost complete loss of volatile substances could be achieved after exceeding $500^{\circ} \mathrm{C}$, leaving the nonvolatile substances (Wang et al. 2019). Hossain et al. (2011) reported the yield of the pyrolysis products from sludge decreased by $8.6 \%$ as the temperature ranged from 300 to $400^{\circ} \mathrm{C}$, while the yield decreased by additional $5 \%$ with the temperature increasing from 500 to $700^{\circ} \mathrm{C}$. Yuan et al. (2015) also investigated the pyrolysis of sludge, and the products yield decreased gradually from $83.3-65.0 \%$ when the temperature raised from 300 to $700^{\circ} \mathrm{C}$. In addition, the ash content and pH of the pyrolysis products under different pyrolysis temperatures were also 
evaluated, as shown in Fig. 2b. With the increase of pyrolysis temperature, the ash content in the products increased gradually, and the ash content did not change as the temperature exceeding $500^{\circ} \mathrm{C}$. The $\mathrm{pH}$ value of the products was less affected by the pyrolysis temperature and it varied between 5 and 5.35 . It is worth noting that the optimum pyrolysis temperature depends on the products intended application.

\subsection{Characterization of the pyrolysis products}

\subsubsection{XRD}

The crystalline patterns of pyrolysis products under different pyrolysis temperatures and $\mathrm{KOH}$ activation concentrations were detected, as can be seen in Fig. 2. The pyrolysis products mainly contained silicon dioxide $\left(\mathrm{SiO}_{2}\right)$ and cadmium cyanide $\left(\mathrm{Cd}(\mathrm{CN})_{2}\right)$ under different pyrolysis temperatures (Fig. $\left.2 \mathrm{a}\right)$, indicating the sludge was rich in inorganic salts after direct pyrolysis modification (Zielińska et al. 2015). When the pyrolysis temperature was at of $300^{\circ} \mathrm{C}$ and $400^{\circ} \mathrm{C}$, another peak $\left(12^{\circ}\right)$ attributing to alumina $\left(\mathrm{Al}_{2} \mathrm{O}_{3}\right)$ was also observed. It showed the existence of $\mathrm{Al}$ element in the sludge, which was an element contained in most municipal sludge (Yin et al. 2019). As the pyrolysis temperature was more than $500^{\circ} \mathrm{C}, \mathrm{Al}_{2} \mathrm{O}_{3}$ disappeared and a new peak indicating zinc iodide ( $\mathrm{Znl}$ ) appeared, mainly due to the further decomposition of the sludge and the secondary reactions of solid residues (Liu et al. 2020). Moreover, a weak peak related to $\mathrm{Na}_{4} \mathrm{SiO}_{4}$, which may be formed from the reaction of sodium salt with $\mathrm{SiO}_{2}$ (Liu et al. 2020), was also observed in all the pyrolysis products. After that the municipal sludge was activated through $\mathrm{KOH}$ solution, the crystalline patterns in the pyrolysis products under $500^{\circ} \mathrm{C}(\mathrm{Fig}$. $2 \mathrm{~b}$ ) was consistent with the pyrolysis products obtained without activation. It suggested that the activation of $\mathrm{KOH}$ had little effect on the composition of pyrolysis products.

\subsubsection{FT-IR}

The surface functional groups of the products obtained at different temperatures and different $\mathrm{KOH}$ activation concentrations were characterized by FT-IR spectra, as shown in Fig. 3. The main peaks detected in different products were similar. The wide band peaks observed at 3433 and $3620 \mathrm{~cm}^{-1} \mathrm{could} \mathrm{be}$ attributed to the $\mathrm{O}-\mathrm{H}$ stretching vibrations. The band peaks at 1630,1033 , and $690 \mathrm{~cm}^{-1}$ were ascribed to the stretching vibrations of $\mathrm{C}=\mathrm{O}, \mathrm{C}-\mathrm{O}$, $-\mathrm{CH} \mathrm{2}^{-}$groups, while the peaks indicating out-of-plane deformation vibrations of $\mathrm{C}-\mathrm{H}$ groups existed at $778 / 800 \mathrm{~cm}^{-1}$ (Liu et al. 2014b). Besides, the peak at $470 \mathrm{~cm}-1$ could be assigned to the Si-O-Si functional group, which was in accordance with the result of XRD analysis. However, the band peaks at $916 \mathrm{~cm}^{-1}$ (C-O-C) and 1099 $\mathrm{cm}^{-1}$ (C-O stretching) disappeared as the pyrolysis temperature increased to $500^{\circ} \mathrm{C}$ (Fig. 3a), which was mainly due to removal of low boiling points components (Zhu et al. 2014). In addition, S300 and S400 appeared characteristic peaks of water at 3619 and $3698 \mathrm{~cm}^{-1}$, indicating that the lower temperature modification was beneficial to the formation of $\mathrm{O}-\mathrm{H}$ (Chen et al. 2018). When the sludge was activated by $\mathrm{KOH}$ before pyrolysis at $500^{\circ} \mathrm{C}$, the peak relevant to $\mathrm{C}-\mathrm{O}$ stretching appeared at $1099 \mathrm{~cm}^{-1}$ in the products compared with that purely polysized at $500^{\circ} \mathrm{C}$ (Fig. $3 \mathrm{~b}$ ), indicating the $\mathrm{KOH}$ activation could enrich the surface functional groups of the products (Liu et al. 2019). Besides, all the different products in Fig. 3 shown different intensity peaks at $2352 \mathrm{~cm}^{-1}$, which were caused by uncontrollable carbon dioxide in the measurement environment (Peng et al. 2017).

\subsubsection{XPS}

To further explore the surface function information of the pyrolysis products, XPS technique was employed and the spectra was shown in Fig. 4. The strongest and sharpest peak from the products indicated the element of $\mathrm{O}$, suggesting the enrichment of oxygen-containing groups (Song et al. 2021). Moreover, there was obvious characteristic peak of oxygen (O-Auger) at $979.7 \mathrm{eV}$ in Fig. 4, which may be attributed to the chemically adsorbed oxygen from air (Zhang et al 2019). When the pyrolysis temperature rose from 300 to $500^{\circ} \mathrm{C}$, the peak intensity of the indicator $\mathrm{C} 1 \mathrm{~s}$ decreased greatly (Fig. $4 \mathrm{a}$ ). If the temperature continued to increase, the peak intensity of the indicator $\mathrm{C} 1 \mathrm{~s}$ had no evident changes, mainly because the volatile carbon had been basically lost at approximately $500^{\circ} \mathrm{C}$ (Yang et al. 2017). Moreover, the peak intensity of the indicator $\mathrm{C} 1 \mathrm{~s}$ in the products obtained by $\mathrm{KOH}$ activation pretreatment was enhanced compared with that purely polysized at $500^{\circ} \mathrm{C}$ (Fig. 4b), which demonstrated the $\mathrm{KOH}$ activation can increase the content of carbon-containing functional groups (Chen et al. 2020b).

In order to better understand the types of carbon and oxygen-containing functional groups, the peaks assigned to $\mathrm{C} 1 \mathrm{~s}$ and $\mathrm{O} 1 \mathrm{~s}$ in different pyrolysis products were fitted separately, and the specific results were shown in Table 1 . The peak relevant to $\mathrm{C} 1 \mathrm{~s}$ can be divided into four independent peaks indicating to $\mathrm{C}$ - $\mathrm{C}$ $(284.6 \mathrm{eV}), \mathrm{C}-\mathrm{O}(285.5 \mathrm{eV}), \mathrm{C}=\mathrm{O}(287.4 \mathrm{eV})$ and $\mathrm{O}-\mathrm{C}=\mathrm{O}(288.8 \mathrm{eV})$, respectively. Whereas the peak relevant to $\mathrm{O} 1 \mathrm{~s}$ can be divided into three independent peaks representing $\mathrm{C}-\mathrm{O}-\mathrm{C}(531.6 \mathrm{eV}), \mathrm{C}-\mathrm{O}(533.0 \mathrm{eV})$ and $\mathrm{O}-\mathrm{C}=\mathrm{O}(530.8 \mathrm{eV})$, respectively (Liu et al. 2014b; Zhang et al. 2017). Compared with the pure pyrolysis at $500^{\circ} \mathrm{C}$, the products obtained by $\mathrm{KOH}$ activation pretreatment showed the decreased content of $\mathrm{C}$ - $\mathrm{C}$ functional groups in $\mathrm{C} 1 \mathrm{~s}$ peak, indicating that the $\mathrm{KOH}$ activation caused the disappearance of volatile compounds and enhancement of surface hydrophobicity for the products (Yu et al. 2012). While the relative content of $\mathrm{C}-\mathrm{O}$ in both $\mathrm{C} 1 \mathrm{~s}$ and $\mathrm{O}$ 1s peaks significantly increased, demonstrating the polarity of pyrolysis products was enhanced after $\mathrm{KOH}$ activation pretreatment (Liu et al. 2014a), which was consistent with the law of FTIR spectra.

Table 1 Binding energy $(\mathrm{eV})$ and content of various types of carbon or oxygen-containing functional groups derived from C1s and $01 \mathrm{~s}$ peaks of different pyrolysis products. 


\begin{tabular}{|c|c|c|c|c|c|c|c|c|c|c|c|c|c|}
\hline \multirow[t]{3}{*}{ Samples } & \multicolumn{8}{|l|}{ C 1s } & \multicolumn{5}{|l|}{$01 \mathrm{~s}$} \\
\hline & \multicolumn{2}{|l|}{$c-c$} & \multicolumn{2}{|l|}{$c-0$} & \multicolumn{2}{|l|}{$C=0$} & \multicolumn{2}{|l|}{$O-C=0$} & \multicolumn{2}{|l|}{$c-0-c$} & \multicolumn{2}{|l|}{$c-0$} & \multirow{2}{*}{$\begin{array}{l}\mathrm{O}-\mathrm{C}=0 \\
\\
\begin{array}{l}\text { Bindin } \\
\text { energ) } \\
\text { (eV) }\end{array}\end{array}$} \\
\hline & $\begin{array}{l}\text { Binding } \\
\text { energy } \\
\text { (eV) }\end{array}$ & $\begin{array}{l}\text { Content } \\
\text { (\%) }\end{array}$ & $\begin{array}{l}\text { Binding } \\
\text { energy } \\
\text { (eV) }\end{array}$ & $\begin{array}{l}\text { Content } \\
\text { (\%) }\end{array}$ & $\begin{array}{l}\text { Binding } \\
\text { energy } \\
\text { (eV) }\end{array}$ & $\begin{array}{l}\text { Content } \\
(\%)\end{array}$ & $\begin{array}{l}\text { Binding } \\
\text { energy } \\
\text { (eV) }\end{array}$ & $\begin{array}{l}\text { Content } \\
\text { (\%) }\end{array}$ & $\begin{array}{l}\text { Binding } \\
\text { energy } \\
\text { (eV) }\end{array}$ & $\begin{array}{l}\text { Content } \\
\text { (\%) }\end{array}$ & $\begin{array}{l}\text { Binding } \\
\text { energy } \\
\text { (eV) }\end{array}$ & $\begin{array}{l}\text { Content } \\
\text { (\%) }\end{array}$ & \\
\hline S300 & 284.66 & 41.63 & 285.57 & 40.17 & 287.38 & 11.21 & 288.86 & 6.99 & 531.62 & 44.43 & 533.07 & 44.29 & 530.1 \\
\hline S400 & 284.68 & 37.45 & 285.59 & 39.62 & 287.49 & 17.41 & 288.80 & 5.52 & 531.63 & 47.15 & 533.09 & 37.56 & $530.2:$ \\
\hline S500 & 284.65 & 50.10 & 285.50 & 23.03 & 287.52 & 21.83 & 288.84 & 5.04 & 531.54 & 24.83 & 532.96 & 24.26 & $529.8^{-}$ \\
\hline S600 & 284.67 & 52.26 & 285.48 & 21.58 & 287.31 & 21.21 & 288.87 & 4.95 & 531.56 & 25.51 & 532.95 & 24.07 & 529.86 \\
\hline S700 & 284.60 & 49.42 & 285.47 & 20.76 & 287.40 & 25.15 & 288.85 & 4.67 & 531.64 & 15.78 & 532.82 & 23.28 & 529.94 \\
\hline KS0.5 & 284.69 & 45.40 & 285.49 & 32.77 & 286.42 & 16.42 & 288.82 & 5.41 & 531.57 & 17.40 & 533.01 & 32.92 & $529.8^{-}$ \\
\hline KS1 & 284.62 & 48.07 & 285.46 & 33.13 & 286.48 & 13.26 & 288.86 & 5.54 & 531.55 & 19.39 & 533.14 & 38.42 & $529.9 \varepsilon$ \\
\hline KS2 & 284.63 & 50.45 & 285.45 & 36.92 & 287.36 & 6.7 & 288.83 & 5.93 & 531.59 & 18.34 & 533.11 & 40.12 & $529.8 \varepsilon$ \\
\hline
\end{tabular}

\subsubsection{Elemental composition}

The elemental composition of municipal sludge, and the products obtained at pyrolysis temperature of $500{ }^{\circ} \mathrm{C}$ as well as the $\mathrm{KOH}(2 \mathrm{~mol} / \mathrm{L})$ activation pretreatment was analyzed, and the results were as shown in Table 2. When the municipal sludge was pyrolyzed, the relative content of $\mathrm{H}$ element reduced, mainly due to the pyrolytic dehydrogenation reaction (Afif et al. 2019). Moreover, the $\mathrm{N}$ element in the pyrolysis products also decreased. Besides, the fact that the $\mathrm{C}$ and $\mathrm{O}$ elements significantly lost was mainly because the organic matter had been volatilized into small molecules of carbon (i.e. $\mathrm{CO}_{2}$ ) during the pyrolysis (Keiluweit et al. 2010). Generally, the higher value of $\mathrm{O} / \mathrm{C}$ or $(\mathrm{O}+\mathrm{N}) / \mathrm{C}$ indicated the stronger polarity of the sample, while the higher value of $\mathrm{H} / \mathrm{C}$ indicated the weaker aromaticity of the sample (Liu et al. 2014a). Therefore, the products after pyrolysis and KOH activation pretreatment showed good polarity and poor aromaticity.

Table 2

Elemental composition of different samples.

\begin{tabular}{|llllllll|}
\hline Samples & $\mathbf{C}(\%)$ & $\mathbf{H}(\%)$ & $\mathbf{N}(\%)$ & $\mathbf{O}(\%)$ & $\mathrm{H} / \mathrm{C}$ & $\mathbf{O} / \mathbf{C}$ & $(\mathrm{O}+\mathrm{N}) / \mathbf{C}$ \\
\hline Sludge & 24.08 & 4.03 & 0.44 & 24.23 & 0.167 & 1.006 & 1.025 \\
S500 & 1.04 & 1.46 & 0.10 & 6.28 & 1.467 & 6.044 & 6.137 \\
\hline KS2 & 0.62 & 0.67 & 0.06 & 5.49 & 1.080 & 8.877 & 8.968 \\
\hline
\end{tabular}

\subsubsection{BET}

To further understand the surface aeras and pore structure characteristics of the samples, the BET technique and BJH method was employed, and the obtained results were shown in Table 3. Compared with the raw municipal sludge, the surface area, pore volume, and pore size for the pyrolysis products increased, suggesting the pyrolysis and $\mathrm{KOH}$ activation pretreatment could enrich the pore structures. Whereas these values reached their maximum at $500{ }^{\circ} \mathrm{C}$, too high or too low temperatures were not conducive to form various pores. This may be due to the blockage of pores by ash or some inorganic salts during pyrolysis at higher temperature, or the closure and collapse of pore structures resulted by the organic matter pyrolysis at lower temperature (Lu et al. 1995; Zielińska et al. 2015). In addition, $\mathrm{KOH}$ activation pretreatment could further increase the values of surface area, pore volume, and pore size for the pyrolysis products. And when the concentration of $\mathrm{KOH}$ was $2 \mathrm{~mol} / \mathrm{L}$, the surface aera of the pyrolysis product reached to be $44.71 \mathrm{~m}^{2} / \mathrm{g}$. Nevertheless, the surface aera of the pyrolysis product decreased to be $28.74 \mathrm{~m}^{2} / \mathrm{g}$ as the $\mathrm{KOH}$ concentration increased to be $4 \mathrm{~mol} / \mathrm{L}$, mainly due to the reaction of $\mathrm{KOH}$ with other substances to form compound which blocked the pores (Wang et al. 2013). Moreover, all the samples showed mesoporous characteristics. 
Table 3

The surface aeras and pore structure characteristics of the samples.

\begin{tabular}{|llll|}
\hline Samples & $\begin{array}{l}\text { Surface area } \\
\left(\mathbf{m}^{2} / \mathbf{g}\right)\end{array}$ & $\begin{array}{l}\text { Total pore volume } \\
\left(\mathbf{c m}^{3} / \mathbf{g}\right)\end{array}$ & $\begin{array}{l}\text { Pore size } \\
(\mathbf{n m})\end{array}$ \\
\hline Sludge & 10.68 & 0.0045 & 2.3537 \\
\hline S300 & 20.69 & 0.0057 & 2.3614 \\
\hline S400 & 27.67 & 0.0107 & 2.3956 \\
\hline S500 & 30.39 & 0.0115 & 2.3895 \\
\hline S600 & 19.34 & 0.0072 & 2.3931 \\
\hline S700 & 13.88 & 0.0049 & 2.3806 \\
\hline KS0.5 & 27.50 & 0.0115 & 2.3956 \\
\hline KS1 & 41.59 & 0.0163 & 2.3930 \\
\hline KS2 & 44.71 & 0.0181 & 2.3854 \\
\hline KS4 & 28.74 & 0.0124 & 2.3941 \\
\hline
\end{tabular}

\subsection{Adsorption of TC by the samples}

\subsubsection{Adsorption capacity}

The adsorption capacity of TC by pyrolysis products were explored at different conditions, and the results were displayed in Fig. 5 . It revealed the pyrolysis products with abundant pore structures provided a large number of adsorption sites, causing the good adsorption property for TC (Xing et al. 2020). The maximum adsorption capacity of TC existed in the pyrolysis products obtained at pyrolysis temperature of $500{ }^{\circ} \mathrm{C}$, and the order was

S500>S400>S300>S600>S700 (Fig. 5a). And when the municipal sludge was pretreated through the activation of $2 \mathrm{~mol} / \mathrm{L} \mathrm{KOH}$, the adsorption capacity of TC could be further enhanced (Fig. 5b). This result was consistent with the previous analysis which showed the effect law of physicochemical characteristics of pyrolysis products on adsorption properties. Chen et al. (2020a) also reported that the specific surface area of the adsorbent played an important role in the adsorption capacity. Higher specific surface area increased the contact area between pyrolysis products and TC, thus augmenting the adsorption. Besides, the polarity and aromaticity of an adsorbent also behaved great contribution to the chemical adsorption. As for the pyrolysis products obtained in this study, the enriched carbon-containing and oxygen-containing functional groups were beneficial to the chemical adsorption of TC on the samples (Lin et al. 2012).

\subsubsection{Adsorption kinetics}

Adsorption kinetics was an important means to investigate the adsorption rate of pollutants onto the sample (Zang et al. 2021). At the initial 120 min of adsorption, the adsorption of TC on various pyrolysis products was remarkable, and the adsorption process reached equilibrium during 420 min. In order to further explore the adsorption kinetic characteristics of TC on the different pyrolysis products, the kinetic models of pseudo-first-order, pseudo-second-order and intra-particle diffusion were employed. The fitting curves were shown in Fig. 6, and the kinetic parameters calculated from the different models were also represented in Table 4 and Table 5. Compared to the pseudo-first-order model and intra-particle diffusion model, the pseudo-second-order kinetic model fitted the data better because of the fitting correlation coefficient of $R^{2}$ was greater than 0.99 . Moreover, the calculated equilibrium adsorption capacity ( $Q_{e}$ ) from the pseudo-second-order kinetic model was closer to the actual adsorption capacity. 
Table 4

Adsorption kinetics parameters of TC on different samples derived from pseudo-first-order and pseudo-second-order kinetic models.

\begin{tabular}{|lllllll|}
\hline Conditions & \multicolumn{3}{l}{ Pseudo-first-order kinetic model } & \multicolumn{3}{l|}{ Pseudo-second-order kinetic model } \\
\cline { 2 - 6 } & $k_{1}\left(\mathbf{m i n}^{-1}\right)$ & $Q_{e}(\mathrm{mg} / \mathrm{g})$ & $R^{2}$ & $k_{2}(\mathrm{~g} / \mathrm{mg} \cdot \mathrm{min})$ & $Q_{e}(\mathrm{mg} / \mathrm{g})$ & $R^{2}$ \\
\hline Pyrolysis temperatures & & & & & \\
\hline $300^{\circ} \mathrm{C}$ & 0.0190 & 20.39 & 0.9542 & 0.0425 & 23.53 & 0.9948 \\
\hline $400^{\circ} \mathrm{C}$ & 0.0450 & 22.20 & 0.9215 & 0.0395 & 25.31 & 0.9982 \\
\hline $500^{\circ} \mathrm{C}$ & 0.0592 & 22.82 & 0.9311 & 0.0385 & 25.96 & 0.9981 \\
\hline $600^{\circ} \mathrm{C}$ & 0.0429 & 19.37 & 0.8949 & 0.0440 & 22.75 & 0.9947 \\
\hline $700^{\circ} \mathrm{C}$ & 0.0240 & 14.19 & 0.8909 & 0.0592 & 16.89 & 0.9883 \\
\hline Activation with different KOH concentrations & & & \\
\hline $0.5 \mathrm{M}$ & 0.0725 & 16.80 & 0.9054 & 0.0523 & 19.12 & 0.9984 \\
\hline $1 \mathrm{M}$ & 0.0250 & 22.48 & 0.8991 & 0.0397 & 25.19 & 0.9955 \\
\hline $2 \mathrm{M}$ & 0.0652 & 24.89 & 0.9151 & 0.0348 & 28.74 & 0.9976 \\
\hline $4 \mathrm{M}$ & 0.0395 & 19.35 & 0.8401 & 0.0434 & 23.04 & 0.9926 \\
\hline
\end{tabular}

Table 5

Kinetic parameters calculated from intra-particle diffusion model for TC adsorption onto different

\begin{tabular}{|c|c|c|c|c|c|c|}
\hline Conditions & $\mathrm{ki}_{1}\left(\mathrm{mg} / \mathrm{g} \mathrm{min} \mathrm{m}^{0.5}\right)$ & $\mathrm{X}_{1}$ & $\mathrm{R}^{2}$ & $\mathrm{ki}_{2}\left(\mathrm{mg} / \mathrm{g} \mathrm{min} \mathrm{m}^{0.5}\right)$ & $\mathrm{x}_{2}$ & $\mathrm{R}^{2}$ \\
\hline \multicolumn{7}{|c|}{ Pyrolysis temperature } \\
\hline $300{ }^{\circ} \mathrm{C}$ & 1.4812 & 1.4394 & 0.9973 & 0.5503 & 10.9377 & 0.9849 \\
\hline $400{ }^{\circ} \mathrm{C}$ & 1.6373 & 4.9641 & 0.9837 & 0.4047 & 16.3659 & 0.9588 \\
\hline $500^{\circ} \mathrm{C}$ & 1.8060 & 5.5680 & 0.9819 & 0.3926 & 17.3636 & 0.9846 \\
\hline $600{ }^{\circ} \mathrm{C}$ & 1.3627 & 4.5303 & 0.9547 & 0.5000 & 11.9254 & 0.9786 \\
\hline $700^{\circ} \mathrm{C}$ & 0.9272 & 2.4262 & 0.9836 & 0.5072 & 5.9052 & 0.9816 \\
\hline \multicolumn{7}{|c|}{ Activation with different $\mathrm{KOH}$ concentrations } \\
\hline $0.5 \mathrm{M}$ & 1.1460 & 5.4753 & 0.9989 & 0.2453 & 13.6831 & 0.9713 \\
\hline $1 \mathrm{M}$ & 1.1877 & 5.2391 & 0.9790 & 0.3986 & 16.0412 & 0.7673 \\
\hline $2 \mathrm{M}$ & 1.7709 & 7.1630 & 0.9385 & 0.4704 & 18.5268 & 0.9891 \\
\hline $4 \mathrm{M}$ & 0.9548 & 6.3358 & 0.9998 & 0.5386 & 11.3300 & 0.9872 \\
\hline
\end{tabular}

\subsubsection{Adsorption isotherms}

Adsorption thermodynamics could largely reflect the adsorption mechanism, thus the adsorption isotherm models of Langmuir and Freundlich was employed to fit the data for the adsorption of different TC initial concentrations onto various pyrolysis products. The adsorption isotherm curves and parameters were shown in Fig. 7. As for the TC adsorption onto products obtained at pyrolysis temperature of $500{ }^{\circ} \mathrm{C}$ (Fig. $7 \mathrm{a}$ ), the Freundlich model was better due to the fitting correlation coefficient of $R^{2}$ was 0.99 , which was much higher than that of derived from Langmuir model $\left(R^{2}=0.77\right)$. This indicated that the adsorption of TC onto S500 was mainly multi-molecule heterogeneous adsorption (Ma et al. 2020), which may be related to coexisting adsorption mechanisms including the $\pi-\pi$ interaction between S500 and TC (Chen et al. 2007; Chen et al. 2021). Furthermore, the value of 1/n was greater than 1, expounding the competition between adsorption sites increased with the equilibrium concentration increasing (Li et al. 2020). However, the TC adsorption onto pyrolysis product pretreated through the activation of $\mathrm{KOH}$ could be greatly described by the Langmuir model (Fig. 7b), suggesting the monomer adsorption mechanism of TC in this situation. And the maximum adsorption capacity of TC reached $50.75 \mathrm{mg} / \mathrm{g}$. This different adsorption mechanism was largely related to the pore structure, polarity, and aromaticity etc. of the adsorbent (Ifthikar et al. 2017).

Furthermore, the XRD and FTIR spectra of S500 and KS2 after adsorption was carried out and presented in Fig. 8. The XRD spectra of S500 and KS2 had no obvious change after adsorption (Fig. 8a and Fig. 8b). As can be seen from Fig. 8c, a new peak at $1099 \mathrm{~cm}^{-1}$ indicating C-0 stretching appeared in the FT-IR spectrum of S500 after adsorption, which may be due to the interaction between TC and S500 (Fan et al. 2016). Meanwhile, it can be seen from Fig. 8d that there was also a new peak appeared at $3620 \mathrm{~cm}^{-1}$ relevant to $\mathrm{O}-\mathrm{H}$ stretching in the FT-IR spectrum of KS2 after adsorption. This should be the O-H functional group of TC, suggesting the adsorption of TC onto the surface of KS2 (Ding et al. 2016; Sun et al. 2013). Consequently, the adsorption of TC onto the pyrolysis products from municipal sludge mainly be attributed to the surface complexation and physical function. 


\section{Conclusions}

In this paper, municipal sludge was employed as raw material and pyrolyzed directly in a muffle furnace without nitrogen protection. The effects of different temperatures and concentrations of activation of $\mathrm{KOH}$ activation on the physicochemical properties of the pyrolysis products were systematically studied. The yield of pyrolysis products ranged from $60-80 \%$ at different temperatures, and the ash content exceeded $80 \%$. The various pyrolysis products had small difference in $\mathrm{pH}$ values ranging from 5 to 5.35 . Furthermore, the pyrolysis products possessed rich surface carbon and oxygen-containing functional groups. As the municipal sludge was activated by $2 \mathrm{~mol} / \mathrm{L} \mathrm{KOH}$ before pyrolysis at $500{ }^{\circ} \mathrm{C}$, the products showed maximum specific surface area of $44.71 \mathrm{~m} / \mathrm{g}$ and maximum adsorption capacity of $50.75 \mathrm{mg} / \mathrm{g}$ toward TC. Adsorption thermodynamics analysis revealed the Freundlich model could better describe the TC adsorption onto pyrolysis products at $500{ }^{\circ} \mathrm{C}$, while the TC adsorption onto pyrolysis product pretreated through the activation of $\mathrm{KOH}$ was more suitable for the Langmuir model. The TC adsorption onto the pyrolysis products from municipal sludge mainly be attributed to surface complexation and physical function.

\section{Declarations}

\section{Author contribution}

Chunmu Yu: Investigation, Writing-original draft. Xiaojuan Chen: Project administration, Funding acquisition, Writing-review \& editing. Ning Li: Visualization, Funding acquisition, Writing-review \& editing. Jieming Chen: Investigation. Liang Yao: Resources. Yu Zhou: Resources. Kaihong Lu: Investigation. Yiqi Lai: Investigation. Xiangyu Lai: Resources.

\section{Funding}

This work has been financially supported by the National Natural Science Foundation of China (21908220), the Doctoral Fund of Ministry of Education of China (2019M663139, 2020M672854), the Natural Science Foundation of Guangdong Province of China (2020A1515010364), and Natural Science Foundation of Guangzhou (202102020825).

\section{Data availability}

All data generated or analyzed during this study are included in this published article. The date and any materials displayed in this manuscript is of availability.

\section{Ethical Approval and Consent to Participate}

The paper does not involve relevant ethical research.

\section{Consent to Publish}

No conflict interest exits in the submission of this manuscript, and manuscript is approved by all authors for publication. The work described was original research that has not been published previously, and not under consideration for publication elsewhere, in whole or in part. All the authors listed have approved the manuscript that is enclosed.

\section{Competing interest}

The authors declare that they have no known competing financial interests or personal relationships that could have appeared to influence the work reported in this paper.

\section{References}

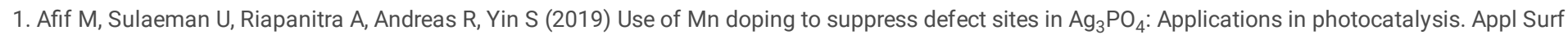
Sci 466:352-357

2. Agrafioti E, Bouras G, Kalderis D, Diamadopoulos E (2013) Biochar production by sewage sludge pyrolysis. J Anal Appl Pyrolysis 101:72-78

3. Barry D, Barbiero C, Briens C, Berruti F (2019) Pyrolysis as an economical and ecological treatment option for municipal sewage sludge. Biomass Bioenerg $122: 472-480$

4. Chen G, Wang C, Tian J, Liu J, Ma Q, Liu B, Li X (2020a) Investigation on cadmium ions removal from water by different raw materials-derived biochars. J Water Process Eng 35:101223

5. Chen W, Duan L, Zhu D (2007) Adsorption of polar and nonpolar organic chemicals to carbon nanotubes. Environ Sci Technol 41:8295-8300

6. Chen W, Gong M, Li K, Xia M, Chen Z, Xiao H, Fang Y, Chen Y, Yang H, Chen H (2020b) Insight into KOH activation mechanism during biomass pyrolysis: Chemical reactions between O-containing groups and $\mathrm{KOH}$. Appl Energy 278:115730

7. Chen Y, Li M, Li Y, Liu Y, Chen Y, Li H, Li L, Xu F, Jiang H, Chen L (2021) Hydroxyapatite modified sludge-based biochar for the adsorption of Cu²+ and Cd ${ }^{2+}$ : Adsorption behavior and mechanisms. Bioresour Technol 321:124413 
8. Chen Y, Wang B, Xin J, Sun P, Wu D (2018) Adsorption behavior and mechanism of $\mathrm{Cr}(\mathrm{VI})$ by modified biochar derived from Enteromorpha prolifera. Ecotoxicol Environ Saf 164:440-447

9. Chen Y, Zhang X, Chen W, Yang H, Chen H (2017) The structure evolution of biochar from biomass pyrolysis and its correlation with gas pollutant adsorption performance. Bioresour Technol 246:101-109

10. Chun Y, Lim M, Yoshikawa K (2012) Characteristics of the product from steam activation of sewage sludge. J Ind Eng Chem 18:839-847

11. Dai X (2020) Present situation and development trend of sludge treatment and disposal in China. Sci 72:30-34

12. Ding C, Cheng W, Wang X, Wu Z, Sun Y, Chen C, Wang X, Yu S (2016) Competitive sorption of Pb(II), Cu(II) and Ni(II) on carbonaceous nanofibers: a spectroscopic and modeling approach. J Hazard Mater 313:253-261

13. Fan S, Tang J, Wang Y, Li H, Zhang H, Tang J, Wang Z, Li X (2016) Biochar prepared from co-pyrolysis of municipal sewage sludge and tea waste for the adsorption of methylene blue from aqueous solutions: kinetics, isotherm, thermodynamic and mechanism. J Mol Liq 220:432-441

14. Hossain MK, Strezov V, Chan KY, Ziolkowsk A, Nelson PF (2011) Influence of pyrolysis temperature on production and nutrient properties of wastewater sludge biochar. J Environ Manage 92:223-228

15. Ifthikar J, Wang J, Wang Q, Wang T, Wang H, Khan A, Jawad A, Sun T, Jiao X, Chen Z (2017) Highly efficient lead distribution by magnetic sewage sludge biochar: sorption mechanisms and bench applications. Bioresour Technol 238:399-406

16. Jin H, Hanif MU, Capareda S, Chang Z, Huang H, Ai Y (2016) Copper(II) removal potential from aqueous solution by pyrolysis biochar derived from anaerobically digested algae-dairy-manure and effect of $\mathrm{KOH}$ activation. J Environ Chem Eng 4:365-372

17. Keiluweit M, Nico PS, Johnson MG, Kleber M (2010) Dynamic molecular structure of plant biomass-derived black carbon (biochar). Environ Sci Technol 44:1247-1253

18. Li Z, Liu X, Wang Y (2020) Modification of sludge-based biochar and its application to phosphorus adsorption from aqueous solution. J Mater Cycles Waste Manag 22:123-132

19. Lin Q, Cheng H, Chen G (2012) Preparation and characterization of carbonaceous adsorbents from sewage sludge using a pilot-scale microwave heating equipment. J Anal Appl Pyrolysis 93:113-119

20. Liu H, Zhang Q, Hu H, Li A, Yao H (2014a) Influence of residual moisture on deep dewatered sludge pyrolysis. Int J Hydrog Energy 39:1253-1261

21. Liu L, Li Y, Fan S (2019) Preparation of $\mathrm{KOH}$ and $\mathrm{H}_{3} \mathrm{PO}_{4}$ modified biochar and its application in methylene blue removal from aqueous solution. Processes 7:891

22. Liu Y, Ran C, Siyal AA, Song Y, Jiang Z, Dai J, Chtaeva P, Fu J, Ao W, Deng Z (2020) Comparative study for fluidized bed pyrolysis of textile dyeing sludge and municipal sewage sludge. J Hazard Mater 396:122619

23. Liu Y, Zhu X, Qian F, Zhang S, Chen J (2014b) Magnetic activated carbon prepared from rice straw-derived hydrochar for triclosan removal. RSC Adv 4:63620-63626

24. Lu G, Low J, Liu C, Lua A (1995) Surface area development of sewage sludge during pyrolysis. Fuel 74:344-348

25. Lu H, Zhang W, Yang Y, Huang X, Wang S, Qiu R (2012) Relative distribution of $\mathrm{Pb}^{2+}$ sorption mechanisms by sludge-derived biochar. Water Res 46:854862

26. Ma J, Zhou B, Zhang H, Zhang W (2020) Fe/S modified sludge-based biochar for tetracycline removal from water. Powder Technol 364:889-900

27. Peng C, Zhai Y, Zhu Y, Wang T, Xu B, Wang T, Li C, Zeng G (2017) Investigation of the structure and reaction pathway of char obtained from sewage sludge with biomass wastes, using hydrothermal treatment. J Clean Prod 166:114-123

28. Shi L, Zhang G, Wei D, Yan T, Xue X, Shi S, Wei Q (2014) Preparation and utilization of anaerobic granular sludge-based biochar for the adsorption of methylene blue from aqueous solutions. J Mol Liq 198:334-340

29. Song J, Messele SA, Meng L, Huang Z, El-Din MG (2021) Adsorption of metals from oil sands process water (OSPW) under natural pH by sludge-based Biochar/Chitosan composite. Water Res 194:116930

30. Sun Y, Shao D, Chen C, Yang S, Wang X (2013) Highly efficient enrichment of radionuclides on graphene oxide-supported polyaniline. Environ Sci Technol 47:9904-9910

31. Li Y, Wang P, Huang C, Yao W, Wu Q, Xu Q (2017) Synthesis and photocatalytic activity of ultrafine $\mathrm{Ag}_{3} \mathrm{PO}_{4}$ nanoparticles on oxygen vacated TiO ${ }_{2}$. Appl Catal B 205:489-497

32. Wang S, Yin Q, Guo J, Zhu L (2013) Influence of Ni promotion on liquid hydrocarbon fuel production over Co/CNT catalysts. Energ Fuel 27:3961-3968

33. Wang X, Chi Q, Liu X, Wang Y (2019) Influence of pyrolysis temperature on characteristics and environmental risk of heavy metals in pyrolyzed biochar made from hydrothermally treated sewage sludge. Chemosphere 216:698-706

34. Xi X, Guo X (2013) Preparation of bio-charcoal from sewage sludge and its performance on removal of Cr(VI) from aqueous solutions. J Mol Liq 183:2630

35. Xing J, Xu G, Li G (2020) Analysis of the complexation behaviors of Cu(II) with DOM from sludge-based biochars and agricultural soil: Effect of pyrolysis temperature. Chemosphere 250:126184

36. Yan Z, Örmeci B, Han Y, Zhang J (2020) Supercritical water oxidation for treatment of wastewater sludge and recalcitrant organic contaminants. Environ Technol Inno 18:100728

37. Yang F, Sun L, Zhang W, Zhang Y (2017) One-pot synthesis of porous carbon foam derived from corn straw: atrazine adsorption equilibrium and kinetics. Environ Sci Nano 4:625-635 
38. Yin Q, Liu M, Ren H (2019) Biochar produced from the co-pyrolysis of sewage sludge and walnut shell for ammonium and phosphate adsorption from water. J Environ Manage 249:109410

39. Yu L, Falco C, Weber J, White RJ, Howe JY, Titirici MM (2012) Carbohydrate-derived hydrothermal carbons: a thorough characterization study. Langmuir 28:12373-12383

40. Yuan H, Lu T, Huang H, Zhao D, Kobayashi N, Chen Y (2015) Influence of pyrolysis temperature on physical and chemical properties of biochar made from sewage sludge. J Anal Appl Pyrolysis 112:284-289

41. Zang S, Zuo Y, Wang J, Liu X, Gomez MA, Wei L (2021) Adsorption removal of roxarsone, arsenite(III), and arsenate(V) using iron-modified sorghum straw biochar and its kinetics. Acta Geochim 40:409-418

42. Zhang J, Shao J, Jin Q, Li Z, Zhang X, Chen Y, Zhang S, Chen H (2019) Sludge-based biochar activation to enhance Pb(II) adsorption. Fuel 252:101-108

43. Zhang X, Zhang S, Yang H, Shao J, Chen Y, Liao X, Wang X, Chen H (2017) Generalized two-dimensional correlation infrared spectroscopy to reveal mechanisms of $\mathrm{CO}_{2}$ capture in nitrogen enriched biochar. P Combust Inst 36:3933-3940

44. Zhu X, Liu Y, Zhou C, Luo G, Zhang S, Chen J (2014) A novel porous carbon derived from hydrothermal carbon for efficient adsorption of tetracycline. Carbon 77:627-636

45. Zielińska A, Oleszczuk P, Charmas B, Skubiszewska-Zięba J, Pasieczna-Patkowska S (2015) Effect of sewage sludge properties on the biochar characteristic. J Anal Appl Pyrolysis 112:201-213

\section{Figures}
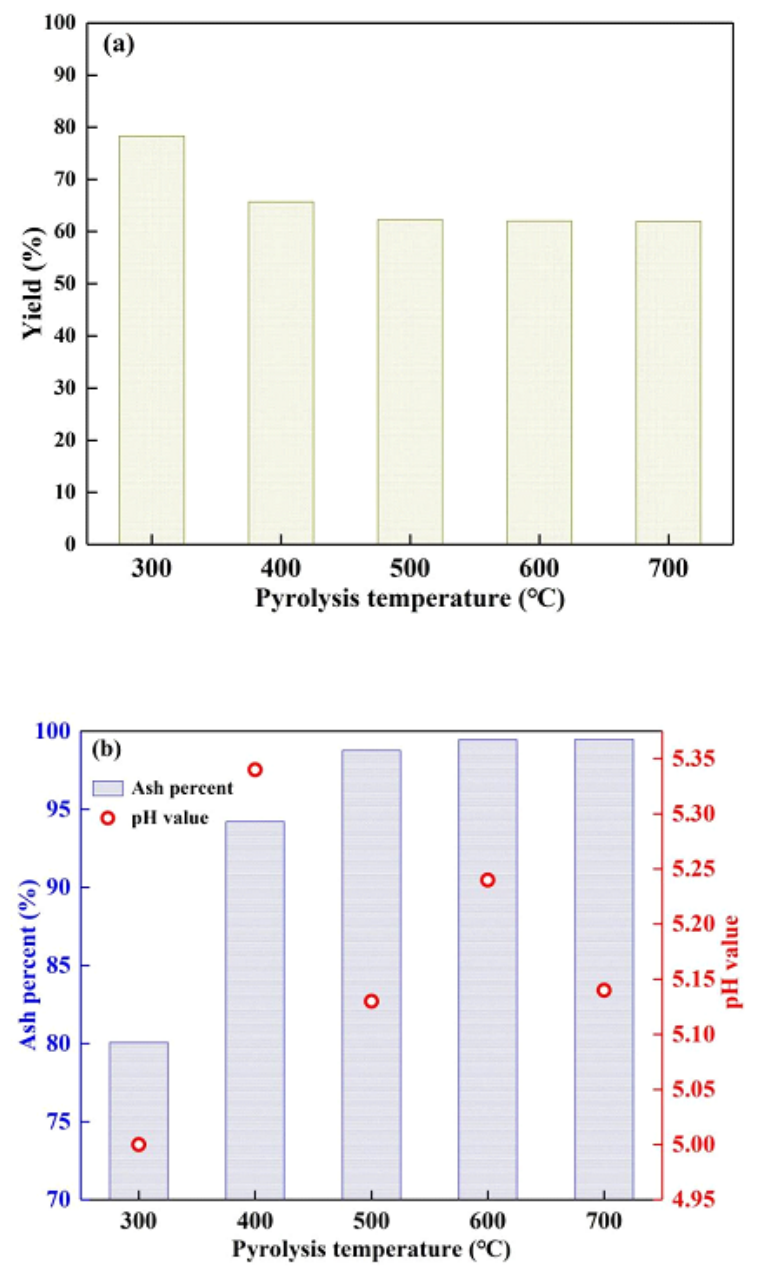

\section{Figure 1}

Yield (a), ash content and pH value (b) of the pyrolysis products from municipal sludge at different pyrolysis temperatures. 

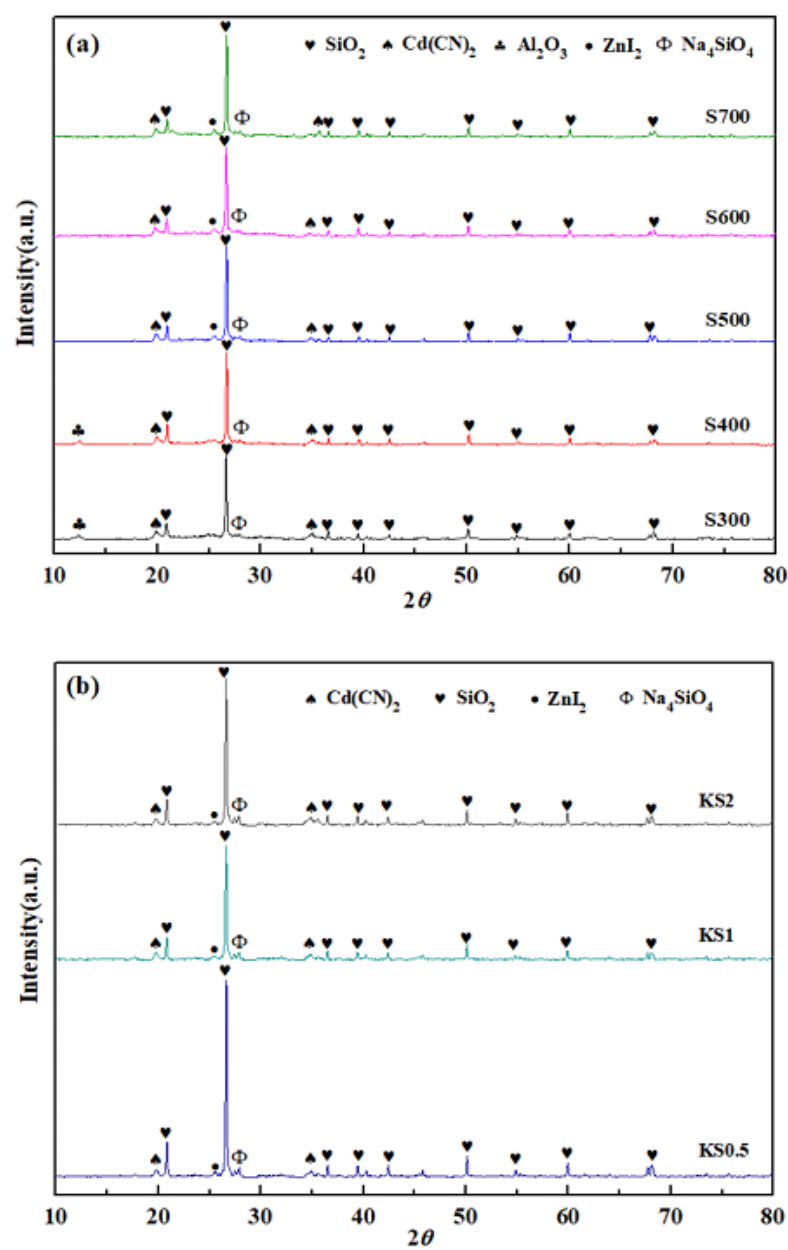

Figure 2

X-ray diffraction (XRD) patterns of pyrolysis products under different pyrolysis temperatures (a) and activation of different KOH concentrations (b). 

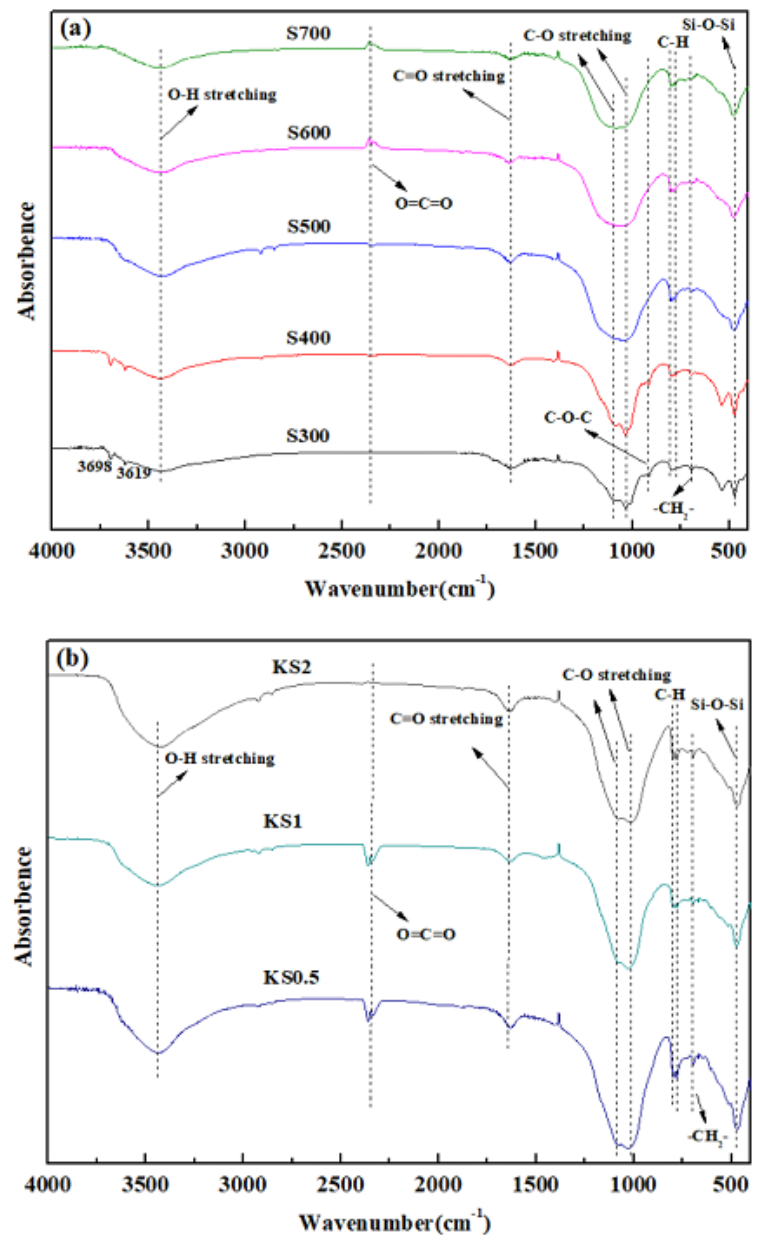

Figure 3

FTIR spectra of products obtained at different pyrolysis temperatures (a) and activation of different KOH concentrations (b). 

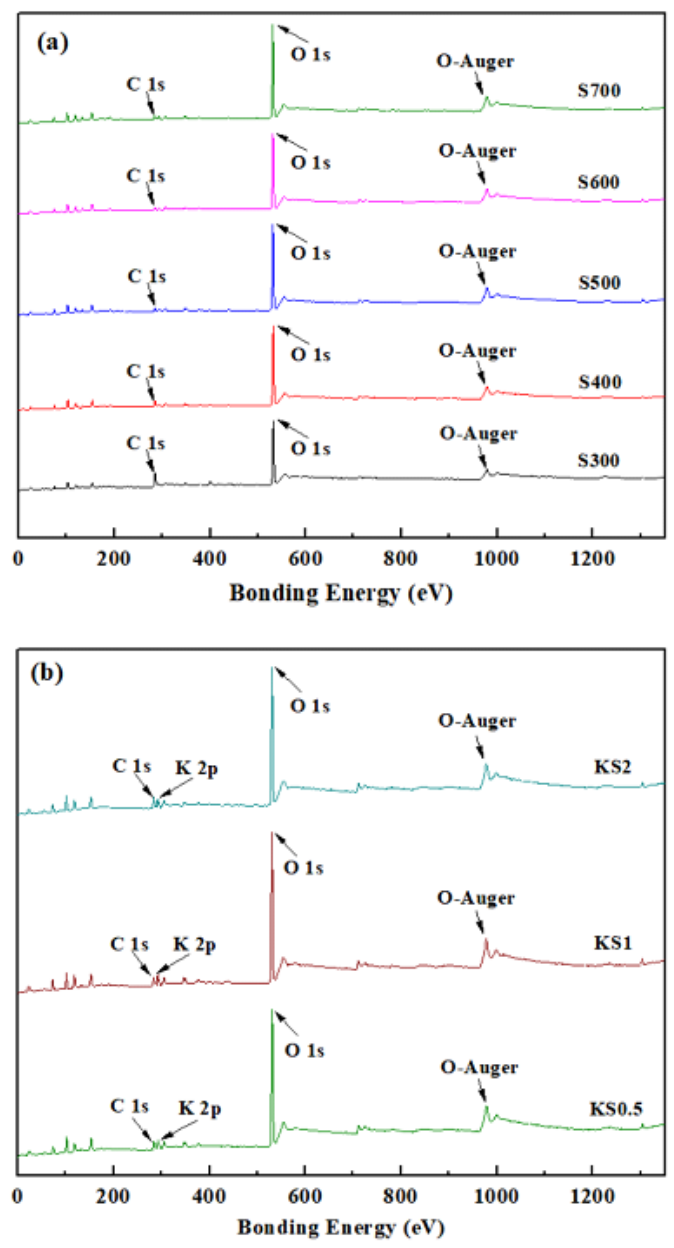

Figure 4

XPS survey spectra of products under different pyrolysis temperatures (a) and activation of different KOH concentrations (b). 

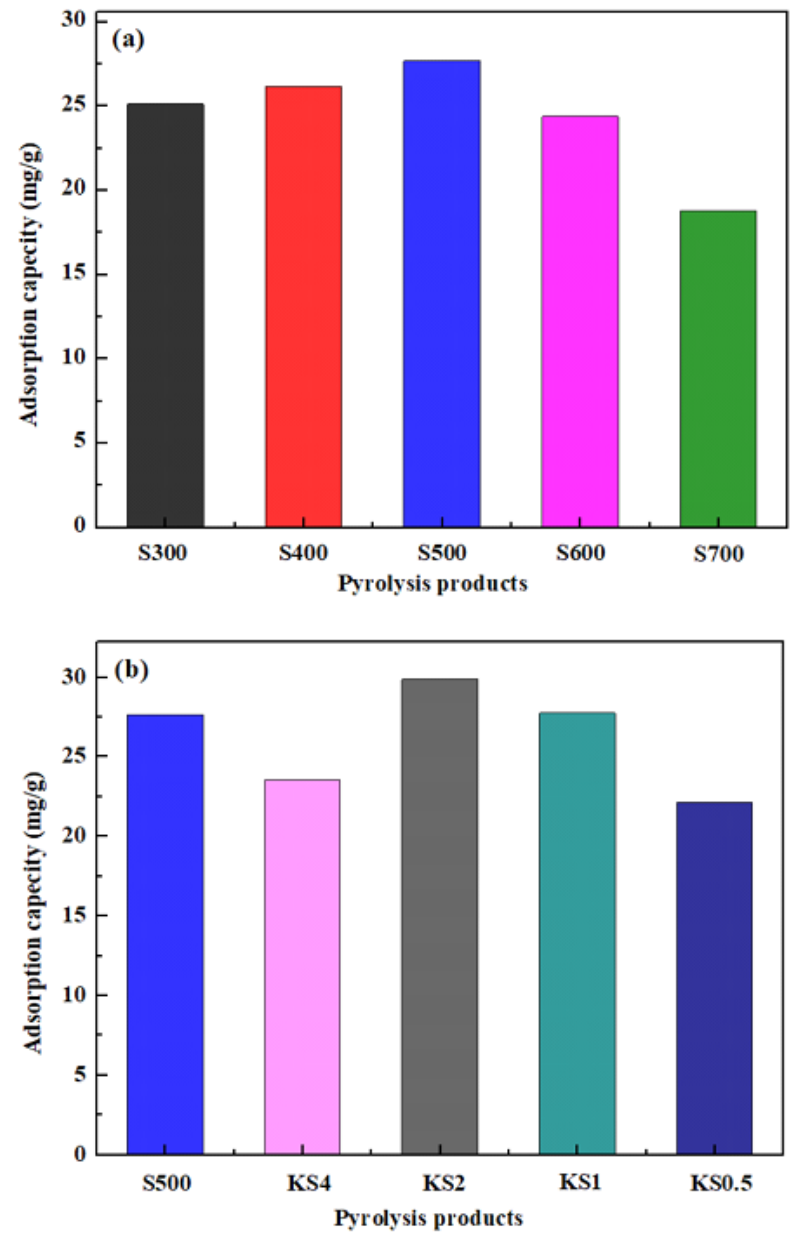

Figure 5

The adsorption capacity ( $\mathrm{mg} / \mathrm{g}$ ) of TC by the samples obtained at different pyrolysis temperatures (a) and activation of different KOH concentrations (b). 

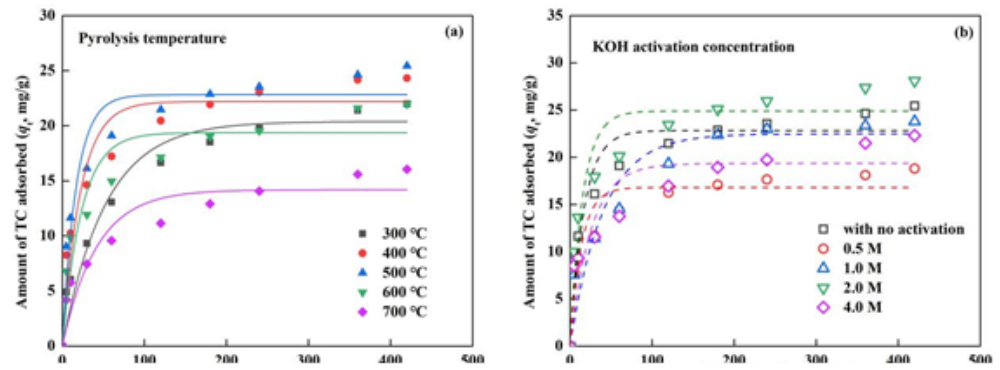

\section{Figure 6}

Pseudo-first-order kinetics model $(a, b)$, pseudo-second-order kinetic model $(c, d)$, and $(e, f)$ intra-particle diffusion model of TC adsorption on the samples obtained at different pyrolysis temperatures and $\mathrm{KOH}$ activation concentrations. 

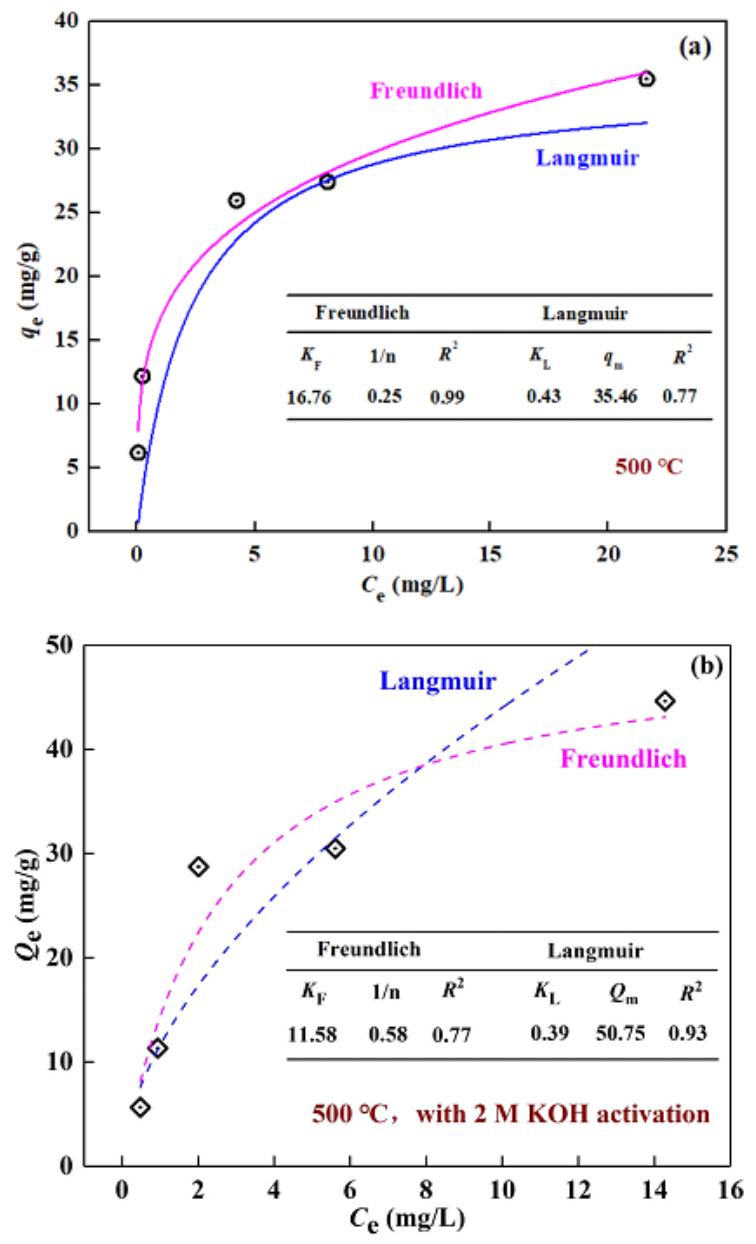

Figure 7

Adsorption isotherm curves and relative parameters of TC adsorption by S500 (a), and KS2 (b). 

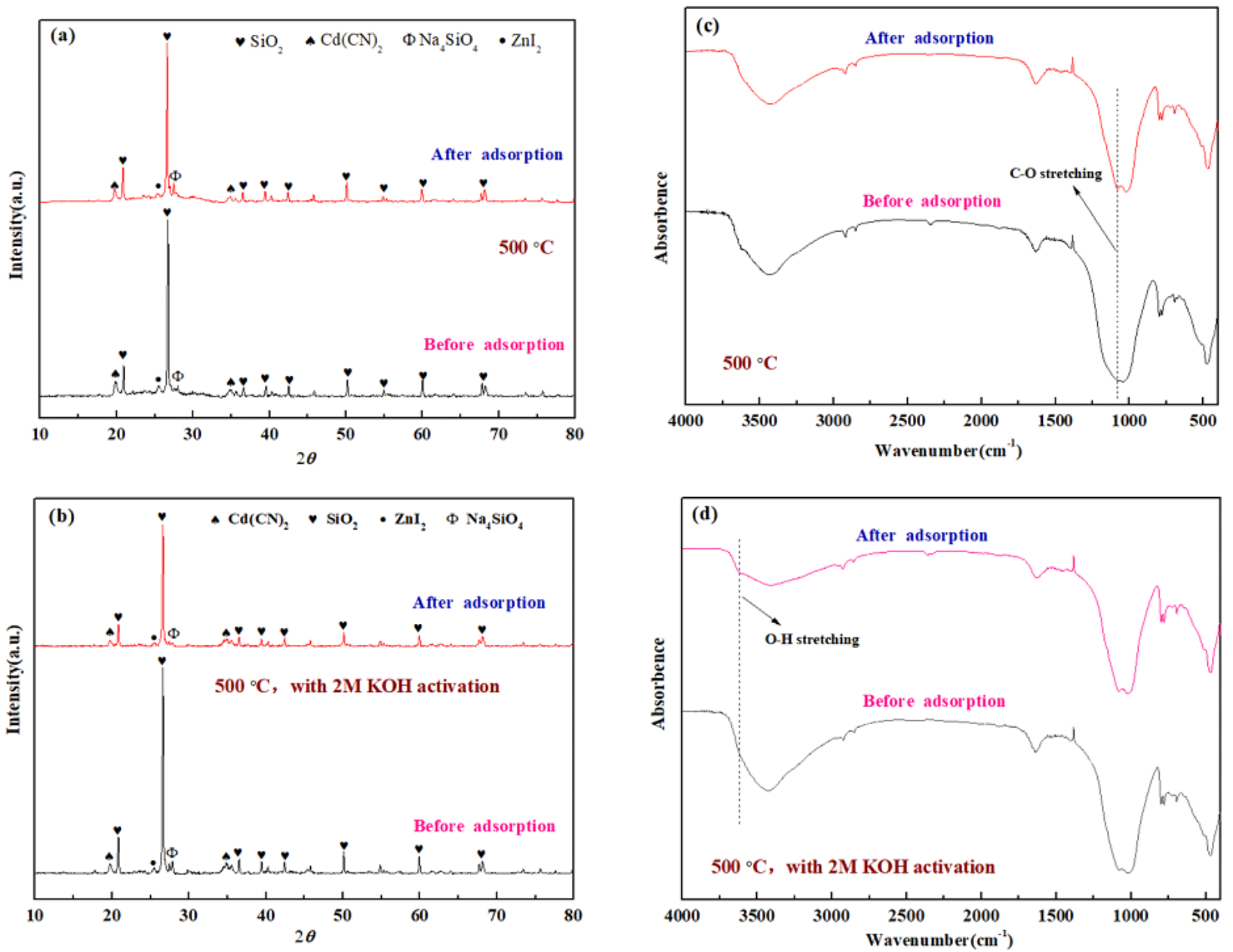

Figure 8

XRD spectra of S500 (a) and KS2 (b), FTIR spectra of S500 (c) and KS2 (d). 